\title{
AS FORMAS DE TRATAMENTO NO TEATRO DO RIO DE JANEIRO DOS SÉCULOS XIX E XX
}

\author{
ANA CAROLINA MACHADO*
}

\begin{abstract}
RESUMO: Este trabalho tem como objetivo analisar o comportamento das formas de tratamento ao interlocutor, que, nesta pesquisa, são consideradas Tradições Discursivas, na variedade do Rio de Janeiro no Português Brasileiro dos séculos XIX e XX. A distribuição dessas estratégias foi investigada em quatorze peças de teatro, à luz da teoria do Poder e da Solidariedade (Brown e Gilman, 2003[1960]). Os resultados apontam para uma predominância de $t u$ até a primeira década do século XX e a preponderância absoluta da forma você, a partir da segunda década do século XX, especialmente nas relações simétricas solidárias e nas relações assimétricas ascendentes. Ressalta-se também o significativo emprego da forma nominal $o(a)$ senhor $(a)$, devido principalmente à presença de altos índices dessa forma nas relações simétricas não-solidárias e nas relações assimétricas ascendentes.

Palavras-chave: estratégias de referência à segunda pessoa; tradições discursivas; cortesia.
\end{abstract}

\begin{abstract}
The main goal of this work is to analyze the behavior of address forms, which, in this research, are considered Discursive Traditions in the variety of Rio de Janeiro in Brazilian Portuguese of the nineteenth and twentieth centuries. The distribution of these strategies was investigated in fourteen plays in the light of Theory of Power and Solidarity (Brown and Gilman, 2003 [1960]). The results point to a predominance of "tu" until the first decade of the twentieth century and the absolute preponderance of the form "você" from the second decade of the twentieth century, especially in the symmetrical solidarity relationships, as well as in ascending asymmetric relationships. It is also worth noting the significant employment of the honorific treatment form "'o(a) senhor(a)", due mainly to the presence of high indices in this form of treatment in the non-symmetrical solidary relationships and the asymmetric ascending relationships.
\end{abstract}

Keywords: reference strategy of second person; discursive traditions; courtesy.

\section{CONSIDERAÇÕES INICIAIS}

A atividade primeira de uma língua é servir como meio de comunicação entre os indivíduos que compõem uma sociedade. Nas palavras de um dos precursores da Sociolinguística, William Labov, é "tal como usada na vida diária por membros da ordem social, este veículo de comunicação com que as pessoas discutem com seus cônjuges, brincam com seus amigos e ludibriam seus inimigos" (Labov, 1998, p.13). Entretanto, essa não é sua única função, visto que a língua, ao longo

* Instituto Federal de Educação, Ciência e Tecnologia do Rio de Janeiro - Campus Rio de Janeiro, Rio de Janeiro, RJ, Brasil. ana.machado@ifrj.edu.br 
da história, serviu como modo de compreender os padrões do comportamento humano que podem se transformar com o tempo e com o espaço.

Para atender às transformações no tempo e no espaço, a língua, muitas vezes, apresentou elementos novos que passaram a variar com os antigos e, até mesmo, depois de um tempo, substitui-los, mudando, assim, a língua, como preconiza a teoria Sociolinguística. No entanto, não só de transformações se compõe a língua; as permanências e as tradições também estão presentes nela, evidenciando que ela também pode ter uma história própria, como mostra a teoria das Tradições Discursivas. Assim sendo, a língua não deve ser vista apenas como um instrumento, mas também como um produto sócio-histórico, fruto da relação mútua entre os indivíduos que compõem ou compuseram uma comunidade, apresentando, desse modo, a capacidade de refletir a heterogeneidade social em diferentes momentos da história bem como de se transformar para suprir novas necessidades sociais.

$\mathrm{Na}$ tarefa de atender não só às necessidades comunicativas de seus falantes, mas também de reproduzir padrões culturais, uma das principais funções da língua parece tem sido auxiliar na atribuição de papéis sociais em uma situação comunicativa. Para tanto, seus falantes servem-se de uma diversidade de estratégias de se dirigir ao outro participante da interação, escolhendo a forma de tratá-lo em um paradigma de formas de tratamento ao interlocutor inerentes à língua. De acordo com Robinson (1977[1972]), dentre as diversas formas linguísticas que contribuem para a reivindicação de um papel por parte do falante e a concessão de outro por este a seu interlocutor, as formas de tratamento possuem uma posição de destaque. Dessa maneira, a escolha pelo emprego de uma dessas formas em uma determinada situação interativa não se dá ao acaso, uma vez que há fatores que influenciam diretamente nessa eleição. Da mesma maneira, ao observar qual dessas formas é usada, torna-se possível, na maioria das vezes, colher informações sobre a relação estabelecida entre os participantes em um determinado contexto comunicativo. Segundo Faraco (1996:57), “(a) dinâmica inter-relação entre fatores sociais e verbais pode ser particularmente visível no sistema de tratamento ao interlocutor, já que esse sistema representa talvez de forma mais direta alguns fundamentos axiológicos da organização do status social"

De um modo geral, a questão do sistema de formas de tratamento e das mudanças operadas em seu interior tem sido abordada pelos estudos linguísticos de duas maneiras: uma baseada nas evoluções sócio-históricas e outra na escolha do falante no momento da interação verbal. Tem-se conhecimento, entretanto, que as alterações no sistema de tratamento ao interlocutor não são condicionadas por razões históricas, sociológicas ou linguísticas separadamente e que, para realizar uma análise criteriosa das estratégias que compõem esse sistema, deve-se, na realidade, buscar a conjunção de muitos fatores que necessitam ser analisados, de modo agrupado, para que não se alcancem resultados falaciosos.

Partindo desses pressupostos, para entender a trajetória experienciada pelas estratégias de referência à segunda pessoa do discurso em português, parece ser fundamental investigar a estreita relação que há entre evolução sócio-histórica, mudança linguística e tradição textual. Cabe, então, ao linguista observar como 
as alterações sociais podem ter impulsionado transformações na língua, que acarretaram outras mudanças no interior do sistema linguístico.

Tomando como fundamento essas considerações e trabalhando com um conjunto de quatorze peças teatrais escritas no Rio de Janeiro dos séculos XIX e $\mathrm{XX}$, este trabalho busca, a partir de estudos já realizados sobre formas de tratamento ao interlocutor: (a) traçar o percurso do sistema de tratamento ao interlocutor na variedade do Rio de Janeiro do Português ao longo dos séculos XIX e XX; e (b) investigar os contextos interacionais em que aparece cada uma das estratégias de tratamento ao interlocutor, a fim de observar, entre outras questões, a restrição ou a expansão, ao longo do tempo, dos contextos interacionais em que estas se realizam, identificando, também, transformações nas próprias situações interacionais que possam ter proporcionado variações no uso das formas de tratamento.

Partindo dos resultados obtidos por trabalhos como os de Paredes Silva (2000), Soto (2001), Sales (2001), Lopes \& Duarte (2003), Lopes \& Machado (2005), Rumeu (2004; 2008), Lopes et al (2018), acredita-se que, (i) no PB do século XIX, embora já se possa notar o emprego de você, há o predomínio de tu; (ii) como já estudado por Paredes Silva (2000), Machado (2006), Lopes et al (2018), a forma você alcança o status de principal estratégia de referência ao interlocutor por volta do segundo quarto do século $\mathrm{XX}$, na variedade do Rio de Janeiro; (iii) com a flexibilização de algumas relações sociais, principalmente, as que se desenvolvem no espaço da família, a partir da segunda metade do século XX, ocorre uma sensível diminuição no índice de emprego de formas de semântica fortemente relacionadas à assimetria, como $o(a) \operatorname{senhor}(a)$.

De antemão, é fundamental sublinhar que se optou por "retrato panorâmico" das formas de tratamento na variedade do Rio de Janeiro do Português dos séculos XIX e XX, por uma explanação geral das mudanças operadas ao longo de dois séculos no sistema de estratégias de referência à segunda pessoa do discurso. Desse modo, assume-se, logo neste primeiro momento, que, muitas vezes, os dados parecerão insuficientes para tecer generalizações e que há uma grande possibilidade de negligenciar questões menores.

\section{AS FORMAS DE TRATAMENTO NOS SÉCULOS XIX E XX: UMA BREVE RETOMADA DE OUTROS ESTUDOS LINGUÍSTICOS}

Em fins do século XVIII e primeiros anos do século XIX, na variedade do Rio de Janeiro, o sistema de tratamento ao interlocutor é integrado basicamente pelo pronome $t u$, para o tratamento íntimo, e por formas de base nominal, $o(a)$ senhor(a), Vossa Excelência (doravante V. Exª) e Vossa Senhoria (doravante V. $\mathrm{S}^{\mathrm{a}}$ ) - - a primeira bem aceita para o trato entre os não íntimos, e as duas últimas, para o tratamento de cortesia, de um inferior a um superior.

De acordo com Lopes e Duarte (2003) e Paredes Silva (2000), também com base em peças teatrais escritas no Rio de Janeiro, há um amplo domínio de $t u$, no século XIX. Entretanto, em ambos os estudos, já é possível observar, ainda que com índices relativamente baixos, o emprego de você (próximos a 10\%, 
segundo Lopes e Duarte, 2003). Esses resultados são bastante semelhantes aos encontrados em trabalhos com corpora de cartas pessoais oitocentistas - Rumeu (2004; 2008), Lopes e Machado (2005) — que também apontam o pronome tu como a principal estratégia de referência ao interlocutor nesse período, mas que identificam também o uso de você, com índices bem mais baixos do que os da principal estratégia.

Sendo assim, no século XIX, a forma você parece ainda não competir diretamente com o pronome $t u$, pois, para estudos como o de Sales (2001), resguarda uma noção de tratamento cerimonioso. Tal fato se deve, de acordo com o próprio Sales (2001), Faraco (1996), Lopes e Duarte (2003), Rumeu $(2004,2008)$ e Machado (2006), entre outros, à origem nominal dessa forma, que foi formada a partir do tratamento cerimonioso Vossa Mercê (doravante V.M.). Segundo esses trabalhos, você, ao longo de sua trajetória, vivencia um processo de pronominalização. Ratificando esses trabalhos, Biederman (1972) afirma que a pronominalização de você se torna bastante evidente nas últimas décadas do século XIX e no século XX, quando, de acordo com a autora, ocorre a substituição de $t u$ por você como forma de tratamento familiar e íntima. No processo de pronominalização de você, observa-se, ainda, a coexistência de V.M. e você, em alguns contextos, em que a expressão original mantém seu emprego, conservando sua forte semântica de assimetria e cortesia, ao passo que, em outros, com a forma já desgastada fonologicamente, perde seu significado inicial.

Tal percepção é confirmada por Barcia (2006), ao investigar cartas de leitores do Rio de Janeiro do século XIX, em que observa que, por um lado, a forma você, ao lado de $t u$, é mais produtiva nas relações entre amigos e cônjuges; e por outro, $V$. M., juntamente com $V . E x^{a}$, predomina quando os destinatários das cartas são o redator do jornal, uma pessoa jurídica ou, ainda, uma pessoa ilustre.

No século XX, trabalhos como os de Paredes Silva (2000) e Machado (2006) apresentam três momentos distintos para as formas de tratamento ao interlocutor no Rio de Janeiro. No primeiro momento, no primeiro quarto do século XX, constata-se a variação entre as formas $t u$, você e $\operatorname{senhor}(a)$ - a primeira utilizada entre íntimos, a segunda, de superior para inferior, e a última, no domínio nãoíntimo e de inferior para superior.

No segundo momento, a partir da década de 30 do século XX, a forma você se converte na principal estratégia de referência ao interlocutor. Ao lado de você, apresenta-se a forma senhor (a), nas relações de simetria não-solidária e de assimetria ascendente. Concomitantemente, nesse período, a forma $t u$ inicia uma trajetória descendente.

No terceiro momento, no último quarto do século XX, além do uso da forma você, o pronome $t u$ ressurge com um emprego não-padrão, ou seja, relacionado a formas verbais de $3^{\mathrm{a}}$ pessoa. Além disso, se, por um lado, na última década do século XX, você co-ocorre com $t u$, agora em seu uso não padrão (associado a formas verbais de $3^{\mathrm{a}}$ pessoa), nas relações já citadas; por outro, o uso de senhor(a) sofre uma sensível diminuição - de cerca de $20 \%$ — nas relações de inferior para superior. 


\section{PRESSUPOSTOS TEÓRICOS}

\subsection{O casamento entre o modelo das Tradições Discursivas e a teoria Sociolinguística}

Considerando que o objetivo principal deste trabalho é descrever as alterações operadas no sistema de tratamento ao interlocutor na variedade do Rio de Janeiro do PB dos séculos XIX e XX, optou-se pelo casamento entre dois modelos teóricos que discutem a mudança linguística: o das Tradições Discursivas e o da Sociolinguística de base laboviana. É importante ressaltar que não serão apresentados profundamente os dois modelos teóricos, mas somente o que, neste estudo, é importante para a explicação das mudanças operadas no paradigma das formas de tratamento.

Segundo Koch e Oesterreicher (1997 apud Kabatek, 2006), Tradições Discursivas (doravante TDs) são todas as formas e fórmulas comunicativas que são recorrentes, tradicionais, cujas fronteiras estão além das estabelecidas para as línguas históricas. Para os autores, ao praticar a atividade do falar, o indivíduo se submete a dois filtros concomitantes até transformar o que deseja em um enunciado, um correspondente à língua histórica e outro, às TDs.

Para ilustrar o conceito de TDs, Kabatek (2006) utiliza um exemplo de um encontro pela manhã entre duas pessoas conhecidas em que há um desejo claro de se saudarem. Nesse caso, não basta somente encontrar uma expressão da língua portuguesa; é necessário que se produza um enunciado como "bom dia", seguindo, assim, uma tradição que é estabelecida pela cultura e que se encontra além das regras gramaticais e do simples conhecimento dos itens lexicais.

Para o estabelecimento de uma TD como material composicional de um gênero textual, são elementos fundamentais: a repetição, que ocorre quando um texto estabelece uma relação com outros textos em um determinado momento da história; e a evocação, que se dá com a repetição dos conteúdos temáticos que são tratados nos textos. Segundo Kabatek (2006), um texto historicamente situado se relaciona com diversos elementos de seu "contexto". Esse "contexto" apresenta inegavelmente um forte conteúdo semântico e pode adquirir um valor simbólico. A repetição (sempre parcial) dos elementos contextuais da primeira enunciação evoca a repetição do texto (ou, ao menos, traz a lembrança do primeiro texto, ou mais amplamente, da TD).

Diante do exposto, considera-se que as estratégias de referência à segunda pessoa são TDs, pois evocam um uso. Se o interlocutor é, por exemplo, uma pessoa mais velha e não se tem com ela nenhum tipo de intimidade, a forma de tratamento mais indicada, evocada, no Português brasileiro contemporâneo, é o(a) senhor (a), e, embora, não haja nenhum impedimento gramatical ou lexical para que se utilize uma estratégia como você, a tradição recomenda que não se empregue essa forma.

Sendo assim, a associação das noções de estratégias de referência ao interlocutor ao conceito de TDs pode ser explicada na medida em que se sabe (a) que, aos falantes de uma determinada língua, estão disponíveis inúmeras formas de natureza nominal, pronominal ou, até mesmo, verbal, de se dirigir à segunda 
pessoa do discurso, como, atualmente na variedade do Rio de Janeiro, o senhor, você, $t u$ ou o simples emprego de um verbo, apresentando desinências númeropessoais de $2^{\mathrm{a}}$ ou $3^{\mathrm{a}}$ pessoas ("vem" ou "venha"), e (b) que, entretanto, não é difícil para qualquer falante de uma língua distinguir, por exemplo, quais dessas formas são mais adequadas ao domínio da formalidade ou da informalidade, qual estratégia deve ser utilizada em um tipo de relação que envolva poder ou não, que seja institucional ou não.

Como já visto, está bastante evidente que o emprego de determinadas formas de se dirigir ao interlocutor está intimamente ligado às relações sociais que se desenvolvem culturalmente e que, dessa maneira, ao se alterarem, as relações sociais acarretam modificações na língua. Além disso, quando ocorrem alterações na história externa de uma língua, inauguram-se novas necessidades comunicativas, que motivam o surgimento de novas TDs. Essas novas TDs provocam mudanças no âmbito da língua. Desse modo, está nas TDs a ligação entre a história externa e interna da língua.

A partir dessa relação entre história externa e história interna, neste trabalho, acredita-se que a mudança no domínio das formas de tratamento possa ocorrer de três modos distintos. O primeiro modo seria a inserção, que ocorre quando há o aparecimento de uma "nova" situação comunicativa, que necessita ser marcada por uma forma de tratamento específica. Já o segundo modo corresponde à expansão linguística, que se relaciona ao alargamento do uso de uma forma linguística para novos contextos situacionais (que, inicialmente, têm algo em comum). Por fim, o terceiro modo é aquele em que há mudança semântica da forma de tratamento. Nesse modo, uma forma expande-se para contextos comunicativos que possuem uma natureza distinta do contexto situacional ao que a forma estava associada anteriormente. A natureza desse novo contexto pode inaugurar, então, uma nova semântica para a forma comunicativa. Utilizando o exemplo da forma V.M., é possível notar que, paulatinamente, ao se expandir e reduzir sua substância fonológica, essa forma atinge novos contextos situacionais, como a relação entre iguais não íntimos, adquirindo um novo significado relacionado, agora, à noção de simetria.

Os dois últimos modelos — o da expansão e o da mudança da semântica - parecem acarretar uma variação linguística, uma vez que, ao ser evocada em uma nova situação comunicativa e modificar sua essência, a "nova forma" passa a representar um tipo específico de relação que não deixa de evocar também a "antiga forma". Para entender melhor a questão da variação e da mudança linguística, utilizaram-se alguns pressupostos da Sociolinguística de base laboviana.

Weinreich, Labov \& Herzog, em Fundamentos empíricos para uma teoria da mudança linguística, de 1968, uma das obras precursoras dos estudos Sociolinguísticos, acreditam que as escolhas realizadas pelos indivíduos ou por um conjunto deles não são aleatórias, mas condicionadas por princípios tanto internos à estrutura linguística quanto inerentes ao sistema social desta. Além disso, os teóricos dessa corrente consideram que, embora possa haver variação no plano da fala (no sentido de ser uma escolha individual), a variação linguística, em geral, está situada no plano do sistema. 
Seria justamente a variabilidade inerente ao sistema o fato que explicaria as mudanças na língua no espaço temporal, sem perda da estruturalidade, visto que, na maioria das vezes, os falantes não percebem que estão vivenciando tais modificações. Para essa sensação de imutabilidade, é essencial a gradualidade das mudanças linguísticas. A esta ideia estão intimamente ligados os processos de coexistência e concorrência entre formas "novas" e "antigas" na língua. Ilustrando, é possível afirmar que a substituição de formas $\underline{x}$ por formas $\underline{y}$ ocorre através de uma fase de transição em que formas $\underline{x}$ e y coexistem, estão em variação, e de uma fase em há a vitória de uma forma x sobre uma forma y. É o que, aparentemente, ocorreu com as formas $t u$ e você, em que a forma mais antiga $t u$ coexistiu com a forma inovadora você, e, em um dado momento, você se sobrepõe a $t u$ e passa a ter seu uso praticamente categórico.

\subsection{A teoria do Poder e Solidariedade: breves considerações}

Como já discutido neste trabalho, no que diz respeito ao sistema de tratamento ao interlocutor, alterações na sociedade são fatores que propiciam mudanças na língua. Dessa maneira, modificações sociais e mais especificamente as alterações nas relações interpessoais afetam diretamente o paradigma das estratégias de referência ao interlocutor.

No trabalho clássico The pronouns of Power and Solidarity, de 1960, Brown e Gilman apresentam um modelo em que as relações estabelecidas entre os participantes de uma situação comunicativa são fundamentais para entender a escolha de pronomes de referência à segunda pessoa do discurso. Segundo os autores, estas relações sociais estão baseadas na dicotomia "poder e solidariedade".

Brown e Gilman (2003[1960]) mostram que o par de conceitos Poder e Solidariedade está presente em todas as formas de interação verbal entre os interlocutores. Por um lado, o poder é compreendido como o controle que uma pessoa exerce sobre outra em uma determinada situação interativa, estando, assim, presente em relações assimétricas, diferenciais ou não recíprocas. Este poder pode ser observado em atributos como idade, geração e autoridade — o pai é superior ao filho, o professor, ao aluno, o patrão, ao empregado.

Por outro lado, a solidariedade pressupõe a existência de forças iguais, de um mesmo nível de hierarquia social decorrente de relações sociais recíprocas ou simétricas. Essas relações simétricas derivam fundamentalmente dos atributos de sexo, parentesco e filiação de grupo, que, por sua vez, estão ligados às ideias de afinidade, semelhança, afeto e agrado.

Desse modo, com relação à distribuição das estratégias de referência ao interlocutor, é possível dizer que o poder é o núcleo do eixo semântico assimétrico, em que é possível observar dois tipos de interação - uma em que o falante detém poder sobre o interlocutor, e outra, em que é o interlocutor que detém poder sobre o falante- , ao passo que a solidariedade é o elemento central do eixo semântico simétrico, em que também é possível observar dois tipos de interação — uma em que a solidariedade entre os participantes da situação comunicativa se faz presente, e outra em que não é possível observar esse atributo. 
Segundo os autores, o uso de formas $V$ (como vous, em francês) está intimamente ligado a relações simétricas em que os componentes da ação não apresentam afinidades (nas relações não solidárias), e a situações assimétricas em que o emissor se encontra em uma situação hierarquicamente inferior à do receptor. Formas $T$ (como $t u$, em francês), ao contrário, estão a serviço de relações simétricas recíprocas e solidárias e de situações assimétricas em que o emissor exerce alguma forma de poder sobre o receptor.

Trabalhos como os de Cintra (1986 [1972]), Faraco (1996), por exemplo, descrevem que, nos primeiros séculos de sua trajetória, você apresentava uma semântica fortemente ligada às noções de assimetria e cortesia - comportamento semelhante ao das denominadas formas $V$; entretanto, aparentemente, essa forma passou a pertencer a domínios que antes eram exclusivos das formas $T$, como evidenciam trabalhos como os de Paredes Silva (1999) e Machado (2006).

\section{O CORPUS}

Neste estudo, optou-se pelo uso de textos teatrais, uma vez que o fenômeno da referência ao interlocutor é exclusividade dos gêneros textuais que apresentam dialogicidade. No interior desse gênero textual, escolheram-se peças escritas no Rio de Janeiro, por autores preferencialmente fluminenses ou que residiram grande parte de suas vidas nesse estado. Além disso, elegeram-se obras que retratassem relações íntimas e/ou, ao menos, informais. Dentre essas obras, há uma especial preferência pelas peças que buscam retratar a vida familiar, apresentando cenários que compreendem, preponderantemente, ambientes privados — casa, pensão onde residem os personagens - do Rio de Janeiro dos séculos XIX e XX. Para essa análise linguística, foram selecionadas quatorze peças, que se encontram elencadas a seguir:

Quadro: A constituição da amostra.

\begin{tabular}{|c|c|c|}
\hline Peça & Autor & Data \\
OS CIÚMES DE UM PEDESTRE & Martins Pena & 1846 \\
O DEMÔNIO FAMILIAR & José de Alencar & 1857 \\
AMOR COM AMOR SE PAGA & França Júnior & 1870 \\
O DEFEITO DE FAMÍLIA & França Júnior & $1870 *$ \\
\hline NÃO CONSULTES MÉDICO & Machado de Assis & 1896 \\
\hline QUEBRANTO & Coelho Neto & 1908 \\
\hline O SIMPÁTICO JEREMIAS & Gastão Tojeiro & 1918 \\
\hline O HÓSPEDE DO QUARTO No 2 & Armando Gonzaga & 1937 \\
\hline DONA XEPA & Pedro Bloch & 1952 \\
\hline O GENRO QUE ERA NORA & Gláucio Gill & 1962 \\
\hline TODA DONZELA TEM UM PAI QUE É UMA FERA & Aurimar Rocha & 1972 \\
\hline
\end{tabular}




\begin{tabular}{|c|c|c|}
\hline COMUNHÃO DE BENS & Alcione Araújo & 1980 \\
\hline INTENSA MAGIA & $\begin{array}{c}\text { Maria Adelaide } \\
\text { Amaral }\end{array}$ & 1995 \\
\hline SÍNDROMES & $\begin{array}{c}\text { Maria Carmen } \\
\text { Barbosa e Miguel } \\
\text { Falabella }\end{array}$ & 2003 \\
\hline
\end{tabular}

\section{AS FORMAS DE TRATAMENTO AO INTERLOCUTOR EM ANÁLISE}

Analisaram-se as estratégias de referência ao interlocutor na função de sujeito explícito ou desinencial associadas a verbos nos modos indicativo e subjuntivo. A seguir, há exemplos das estratégias sob investigação.

(01) PEDESTRE - $\underline{\boldsymbol{T} \boldsymbol{u}}$ és capaz de fugir daqui? (Os ciúmes de um pedestre, 1846)

(02) ELIANA — Fala aí, vó! Porra, como tu tá gorda! Que loucura! (Síndromes, 2003)

(03) ROBERTO, com energia - Ah, sois o seu assassino? O assassino de minha filha? Ah, não saireis de minhas mãos! (Os ciúmes de um pedestre, 1846)

(04) PEDESTRE — Sim, sim, está morta... Mas vós lhe dareis vida por um navio... vinde... silêncio... Dar-vos-ei um navio que ela me fez perder... (Os ciúmes de um pedestre, 1846)

(05) ROBERTO, com energia - Ah, sois o seu assassino? O assassino de minha filha? Ah, não saireis de minhas mãos! (Os ciúmes de um pedestre, 1846)

(06) CARLOTINHA - É injusto, mano; aquele amor não se finge. Quando ela me recitou os versos que você lhe mandou... (O demônio familiar, 1857)

(07) MACEDO - Você não quer admitir que sou um coroa ainda muito enxuto, não é? Mas pode deixar, meu bem. Eu vou morrer apaixonado por você. (O genro que era nora, 1972)

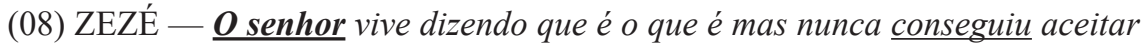
os outros como são. (Intensa Magia, 1995)

(09) PEDRO - Pedro tinha arranjado casamento bom; viúva rica, duzentos contos, quatro carros, duas parelhas, sala com tapete. Mas o senhor estava enfeitiçado por sinhá Henriqueta e não queria saber de nada. Precisava trocar, Pedro trocou. (O demônio familiar, 1857)

(10) EDUARDO - Não se agonie, minha mãe, eu mandarei fazer uma pequena divisão no quintal. Deste lado Carlotinha terá o seu jardim; do outro $\underline{\text { V.Mce. }}$ 
mandará preparar a sua horta. (O demônio familiar, 1857)

(11) JOSEFINA - Vosmecê nunca há de perder o sestro de contar tudo quanto ouve e $\underline{\boldsymbol{v}}$. . ( $O$ defeito de familia, 1870)

(12) PEDESTRE - [...] Que ordena vossa senhoria? (Os ciúmes de um pedestre, 1846)

(13) MANFREDO - Madame deve ter uma grande sensibilidade artística. ( Dona Xepa, 1952)

(14) PEDESTRE - Ah, a menina tem namorados, recebe cartinhas e quer casarse contra a minha vontade [...] (Os ciúmes de um pedestre, 1846)

\section{AS FORMAS DE TRATAMENTO AO INTERLOCUTOR: O PANORAMA GERAL}

Nesta sessão, serão apresentadas as formas de referência à segunda pessoa do discurso na função de sujeito explícito ou desinencial nas quatorze peças escritas no Rio de Janeiro dos séculos XIX e XX. A metodologia para distinguir as formas nulas de terceira pessoa foi a seguinte.

Foram consideradas formas relacionadas:

(i) a você, aquelas em que este pronome se apresenta em outros dados como sujeito preenchido na mesma relação (personagem $\mathrm{A}$ fala ao personagem $\mathrm{B}$, não necessariamente no mesmo ato de fala);

(15) MACEDO - Você não quer admitir que sou um coroa ainda muito enxuto, não é? Mas pode deixar, meu bem. Eu vou morrer apaixonado por você. (PB - O genro que era nora, 1972)

(ii) à forma $o(a)$ senhor (a), somente aquelas em que estas formas se apresentam em outros dados como sujeito preenchido na mesma relação (personagem $\mathrm{C}$ fala ao personagem D), como mostra o exemplo 16.

(16) PEDRO - Pedro tinha arranjado casamento bom; viúva rica, duzentos contos, quatro carros, duas parelhas, sala com tapete. Mas o senhor estava enfeitiçado por sinhá Henriqueta e não queria saber de nada. Precisava trocar, Pedro trocou. (PB - O demônio familiar, 1857)

(iii) a formas nominais como: a menina, a mãe, V. M., V.Ex $x^{a \ldots .,}$, entre outras, do mesmo modo como com as estratégias relacionadas à forma $o(a)$ senhor $(a)$, somente aquelas em que estas formas se apresentam em outros dados como sujeito preenchido na mesma relação (personagem $\mathrm{E}$ fala ao personagem $\mathrm{F}$ ), como mostra o exemplo 19 , já apresentado anteriormente. 
(19) PEDESTRE - Ah, a menina tem namorados, recebe cartinhas e quer casarse contra a minha vontade [...] (PB - Os ciúmes de um pedestre, 1846

É fundamental ressaltar que, a fim de sintetizar os resultados, agruparamse, na análise, os dados aproximadamente por quartos de século. Assim, as obras compreendidas entre os anos de 1846 e 1870 apresentam-se como XIX (3); a de 1896, como XIX (4); as de 1908 e 1918, como XX (1), as de 1937 e 1952, como XX (2), as de 1962 e 1972, como XX (3), e as de 1980, 1995 e 2003, como XX (4).

Tabela 1: A distribuição das formas na função de sujeito pleno e nulo na amostra.

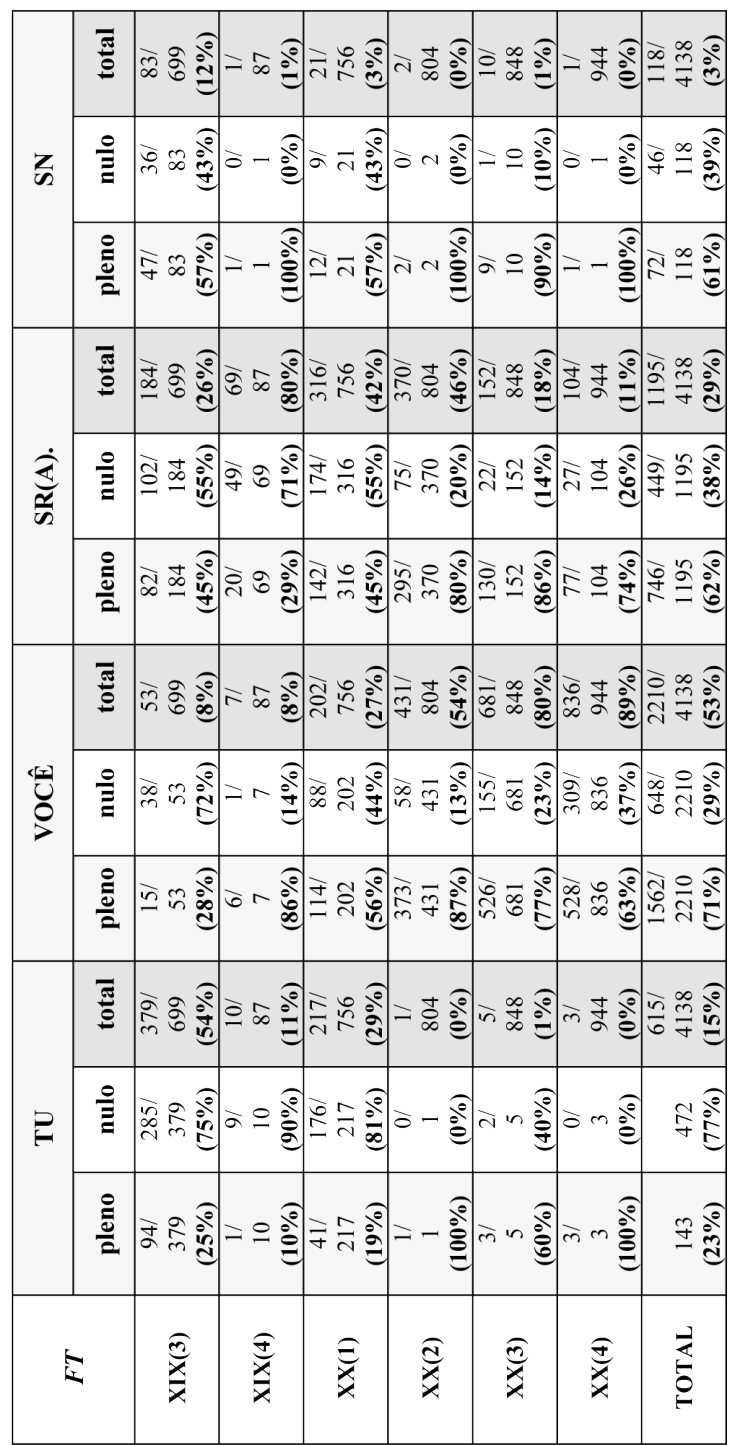


Antes de se iniciar a análise, cabe esclarecer que foram identificados apenas um dado de $V . S^{a}$ e um de $V . E x^{a}$, nas obras do primeiro período sob investigação, e que estes foram agrupados com as sintagmas nominais (doravante SNs). Excluíram-se da tabela os dados de vós: sete, no terceiro quarto do século XIX (correspondente a 7\% do total de dados), e três, no primeiro quarto do século XX (correspondente a $1 \%$ do total de dados). Não figuram na tabela também os dados de V.M. (e variantes): vinte e dois, no primeiro quarto do século XIX.

Em linhas gerais, nota-se, na amostra sob análise, o predomínio das formas pronominais - $t u$ e você — sobre as demais, sendo, entre as formas pronominais - $t u$ mais frequente nas obras do século XIX e do primeiro quarto do século XX, e você, nas obras a partir do segundo quarto do século XX. Tais resultados confirmam os apontamentos feitos por Paredes Silva (1999) de que o pronome você passa a aparecer de modo mais sistemático a partir da década de 1920, quando se observa uma revolução na linguagem literária promovida pelo movimento modernista.

Ressalta-se que, apesar da predominância do uso de você, no último quarto do século XX, ocorre o reaparecimento do pronome $t u$, agora, associado à marca correspondente à terceira pessoa do singular. Trabalhos como os de Paredes Silva (1999, 2000 e 2003), Lopes, Couto \& Duarte (2005) e Menon \& LoregianPenkal (2002) constatam também essa combinação de $t u$ com formas verbais de $3^{\mathrm{a}}$ pessoa.

No que diz respeito à forma $o(a)$ senhor $(a)$, notam-se frequências bastante expressivas nas obras compreendidas entre o último quarto do século XIX e a primeira metade do século XX. As exceções ficam por conta das peças situadas nos extremos da tabela. Por um lado, nas peças do terceiro quarto do século XIX, além do emprego de outras formas de tratamento como vós, V.M. (e variantes) e SNs que concorrem com o uso de $o(a)$ senhor(a) para o tratamento formal, há o uso do pronome $t u$, que é a forma predominante. Por outro, observa-se uma significativa queda da frequência de uso de $o(a)$ senhor $(a)$, em relação às outras obras da amostra, a partir da segunda metade do século XX. Tal fato pode estar relacionado, nas obras, a uma possível flexibilização das relações de poder no período pós-Segunda Guerra Mundial, em que o valor adquirido pela relação valeria mais do que o valor imposto pela tradição. Nessas obras, observa-se o amplo predomínio do pronome você.

Com relação ao preenchimento do sujeito, é interessante notar que a forma $t u$ aparece predominantemente de forma nula, no século XIX e primeiro quarto do século XX. Os resultados desse pronome nos demais períodos são insignificantes pelo pequeno número de ocorrências, sendo impossível afirmar este apresentava um comportamento de sujeito pleno. Já a forma você é preponderantemente plena, exceção feita ao terceiro quarto do século XIX. Com relação ao preenchimento de $o$ (a) senhor (a), observa-se que, no século XIX e primeiro quarto do século $\mathrm{XX}$, os usos são predominantemente nulos e a partir do segundo quarto do século $\mathrm{XX}$, essa forma passa a ter maiores índices de preenchimento do que de não preenchimento. Tal fato pode estar relacionado ao alçamento de você ao posto de principal estratégia pronominal de tratamento, o que fez com que a marca verbal 
de terceira pessoa precisasse vir acompanhada da forma a que está ligada, para evitar dúvida com relação à forma escolhida para o tratamento do interlocutor .

\section{AS FORMAS DE TRATAMENTO AO INTERLOCUTOR: AANÁLISE DOS RESULTADOS DAS RELAÇÕES ESTABELECIDAS ENTRE OS INTERLOCUTORES}

Para a elaboração de um percurso histórico das formas de tratamento ao interlocutor nos dois últimos séculos relacionadas a seus distintos valores pragmáticos, são objetivos desta seção: (1) identificar, através da observação das frequências de uso, as formas de tratamento mais empregadas nas relações simétricas e assimétricas; (2) apresentar o campo de emprego de cada forma de tratamento na variedade do Rio de Janeiro, no período desse estudo; (3) descrever a passagem de determinados tratamentos para o campo anteriormente ocupado por outros; (4) analisar as possíveis mudanças no interior de determinadas relações sociais.

Com base na teoria do Poder e da Solidariedade (Brown e Gilman, 2003 [1960]), será tomada a seguinte tipologia: (a) simétricas solidárias, em que não há poder e é observada solidariedade, (b) simétricas não-solidárias, em que não existe poder e também não é verificada solidariedade, (c) assimétricas descendentes, em ocorre poder, e o falante é o possuidor deste ou (d) assimétricas ascendentes, em que se apresenta poder, e é o interlocutor o possuidor deste.

\subsection{A distribuição das formas nas relações simétricas}

As relações simétricas são aquelas em que nenhum dos participantes da situação comunicativa apresenta poder sobre o outro. Esse tipo de relação orientase, segundo Brown e Gilman (2003[1960]), pelo parâmetro da solidariedade, pressupondo a existência de forças iguais, de um mesmo nível de hierarquia. Tais relações também podem ser conhecidas como horizontais, na categorização de Kerbrat-Orecchioni (2006). Para a autora, esse tipo de relação é constituído por interações em que os interlocutores se conhecem pouco, muito, ou não se conhecem, possuem ou não laço sócioafetivo que os une, entre outras, mas não há poder envolvido na relação.

\subsubsection{As relações simétricas solidárias}

Na amostra em estudo, as relações simétricas solidárias foram encontradas na interação entre casais, irmãos e amigos. Como se trata de relações em que não há poder envolvido e os participantes se guiam pelo parâmetro da solidariedade, esperava-se, com relação às TDs, que se evocasse o emprego de pronomes, que são tradicionalmente as formas de tratamento mais íntimo.

$\mathrm{Na}$ análise dessas relações, foram identificados $\mathbf{1 7 4 8}$ dados, distribuídos do seguinte forma na amostra: 
Tabela 2: A distribuição dos dados nas relações simétricas solidárias na amostra.

\begin{tabular}{|c|c|c|c|c|c|}
\hline FT & TU & VOCÊ & $\operatorname{Sr}(a)$. & SN & TT \\
\hline XIX (3) & $\begin{array}{l}218 / 308 \\
(\mathbf{7 1 \%})\end{array}$ & $\begin{array}{l}29 / 308 \\
(\mathbf{9 \%})\end{array}$ & $\begin{array}{l}56 / 308 \\
(\mathbf{1 8 \%})\end{array}$ & $\begin{array}{l}5 / 308 \\
(\mathbf{2 \%})\end{array}$ & 308 \\
\hline XIX (4) & $\begin{array}{c}1 / 6 \\
(\mathbf{1 7 \%})\end{array}$ & $\begin{array}{c}5 / 6 \\
(\mathbf{8 3} \%)\end{array}$ & - & - & 6 \\
\hline $\mathbf{X X}(1)$ & $\begin{array}{l}92 / 122 \\
(\mathbf{7 5 \%})\end{array}$ & $\begin{array}{l}9 / 122 \\
(7 \%)\end{array}$ & $\begin{array}{l}21 / 122 \\
(\mathbf{1 7 \%})\end{array}$ & - & 122 \\
\hline$X X(2)$ & $\begin{array}{l}1 / 241 \\
(0 \%)\end{array}$ & $\begin{array}{l}227 / 241 \\
(\mathbf{9 4 \% )})\end{array}$ & $\begin{array}{l}13 / 241 \\
(\mathbf{5 \%})\end{array}$ & - & 241 \\
\hline $\mathbf{X X}(3)$ & $\begin{array}{l}5 / 496 \\
(\mathbf{1 \% )}\end{array}$ & $\begin{array}{l}491 / 496 \\
(99 \%)\end{array}$ & - & - & 496 \\
\hline $\mathbf{X X}(4)$ & - & $\begin{array}{l}571 / 575 \\
(99 \%)\end{array}$ & $\begin{array}{l}4 / 575 \\
(1 \%)\end{array}$ & - & 575 \\
\hline Total & $\begin{array}{c}317 / 1748 \\
(\mathbf{1 8 \%})\end{array}$ & $\begin{array}{c}1332 / 1748 \\
(\mathbf{7 6 \% )}\end{array}$ & $\begin{array}{c}94 / 1748 \\
(6 \%)\end{array}$ & $\begin{array}{c}5 / 1748 \\
(\mathbf{0 \%})\end{array}$ & 1748 \\
\hline
\end{tabular}

Inicialmente, pode-se fazer uma distinção entre as peças do terceiro quarto do século XIX e do primeiro quarto do século XX e as obras datadas a partir do segundo quarto deste século. Tal distinção se deve, por um lado, à quantidade de estratégias de tratamento utilizadas - verifica-se, além dos pronomes $t u$ e você, o emprego de formas de base nominal como o(a) senhor (a) e de SNs - , por outro, uma menor quantidade de estratégias nas obras encontradas a partir do segundo quarto do século XX, em que preponderam as formas pronominais.

O uso de pronomes, conforme o esperado, predomina neste tipo de relação. Nas obras do terceiro quarto do XIX e do primeiro quarto do século XX, a estratégia mais produtiva é o pronome $t u$. Cabe ressaltar que os dados do último quarto do século XIX têm pouca significância, correspondem a apenas seis na obra de Machado de Assis, Não consultes médico, de 1896, em que prevalece o uso de você sobre $t u$. Para entender esses dados na obra de Machado de Assis, são muito interessantes as constatações de Biderman (1975), que, ao analisar cartas pessoais também desse autor, verificou o emprego pronome $t u$ com os íntimos até o final da década de 1870, ao passo que, nas últimas décadas do século XIX, notou que se empregava quase que exclusivamente a forma você para os mesmos.

Enquanto, no terceiro quarto do século XIX e primeiro do XX, tu prevalece sobre você, nas obras datadas a partir do segundo quarto do século $\mathrm{XX}$, o uso de você é praticamente categórico, com índices sempre acima dos 90\%.

Ratificam-se, assim, os resultados obtidos, para o PB, por Paredes Silva (2000), Soto (2001), Sales (2001) e Lopes \& Duarte (2003), Lopes et al (2018), que afirmam que a forma de tratamento mais produtiva nas relações simétricas 
solidárias no século XIX é o pronome $t u$, bem como os de Paredes Silva (2000) e Machado (2006), que apontam você como a estratégia mais produtiva nessas relações a partir da década de 1930.

\subsubsection{As relações simétricas não-solidárias}

Entre todos os tipos de relação, neste estudo, acredita-se que as mais difíceis de serem identificadas são as relações simétricas não-solidárias, visto que as "leis" que regem o uso das estratégias de referência à segunda pessoa entre não-íntimos são bastante "maleáveis". De acordo com Biederman (1972), uma pessoa de uma mesma classe social pode alternar o tratamento o(a) senhor(a) com você, uma vez que pessoas de educação mais conservadora utilizam o tratamento mais formal, evidenciando, assim, que se trata de uma regra flutuante, que depende unicamente do indivíduo.

Neste estudo, as relações simétricas não-solidárias são constituídas pelas interlocuções entre indivíduos desconhecidos ou conhecidos não amigos, sem nenhum vínculo familiar. Agrupam-se também sob este rótulo as relações entre sogro(a) e genro/nora. Supunha-se que as TDs evocadas nesse tipo de relação fossem de base nominal, uma vez que se esperava o emprego de estratégias mais formais.

Para esse tipo de relação, encontraram-se, nas obras que constituem a amostra, 1292 dados, distribuídos do seguinte modo:

Tabela 3: A distribuição dos dados nas relações simétricas não-solidárias na amostra.

\begin{tabular}{|c|c|c|c|c|c|c|}
\hline FT & TU & VOCÊ & VÓS & SR. & SN & TT \\
\hline XIX (3) & $\begin{array}{l}20 / 136 \\
(\mathbf{1 5 \%})\end{array}$ & $\begin{array}{l}15 / 136 \\
(\mathbf{1 1 \% )}\end{array}$ & $\begin{array}{l}7 / 136 \\
(5 \%)\end{array}$ & $\begin{array}{l}93 / 136 \\
(\mathbf{6 8 \%})\end{array}$ & $\begin{array}{l}1 / 136 \\
(\mathbf{1 \% )}\end{array}$ & 136 \\
\hline XIX (4) & $\begin{array}{c}8 / 76 \\
(\mathbf{1 1 \%})\end{array}$ & $\begin{array}{l}2 / 76 \\
(\mathbf{3 \%})\end{array}$ & - & $\begin{array}{l}66 / 76 \\
(\mathbf{8 7 \%})\end{array}$ & - & 76 \\
\hline $\mathbf{X X}(1)$ & $\begin{array}{l}48 / 314 \\
(\mathbf{1 5 \%})\end{array}$ & $\begin{array}{l}\text { 70/314 } \\
(\mathbf{2 2 \%})\end{array}$ & - & $\begin{array}{c}186 / 314 \\
(\mathbf{5 9 \%})\end{array}$ & $\begin{array}{c}10 / 314 \\
(3 \%)\end{array}$ & 314 \\
\hline $\mathbf{X X}(2)$ & - & $\begin{array}{l}155 / 444 \\
(35 \%)\end{array}$ & - & $\begin{array}{l}288 / 444 \\
(65 \%)\end{array}$ & $\begin{array}{l}1 / 444 \\
(0 \%)\end{array}$ & 444 \\
\hline XX (3) & - & $\begin{array}{l}53 / 132 \\
(\mathbf{4 0 \% )}\end{array}$ & - & $\begin{array}{l}69 / 132 \\
(\mathbf{5 2 \%})\end{array}$ & $\begin{array}{c}10 / 132 \\
(\mathbf{8 \%})\end{array}$ & 132 \\
\hline $\mathbf{X X}(4)$ & $\begin{array}{l}1 / 190 \\
(\mathbf{1 \% )}\end{array}$ & $\begin{array}{c}147 / 190 \\
\mathbf{( 7 7 \% )}\end{array}$ & - & $\begin{array}{l}41 / 190 \\
(\mathbf{2 2 \%})\end{array}$ & $\begin{array}{l}1 / 190 \\
(\mathbf{1 \% )}\end{array}$ & 190 \\
\hline Total & $\begin{array}{c}\text { 77/1292 } \\
(\mathbf{6 \%})\end{array}$ & $\begin{array}{c}442 / 1292 \\
(\mathbf{3 4 \% )}\end{array}$ & $\begin{array}{c}\text { 7/1292 } \\
(\mathbf{1 \% )}\end{array}$ & $\begin{array}{c}743 / 1292 \\
(\mathbf{5 7 \% )}\end{array}$ & $\begin{array}{c}23 / 1292 \\
(\mathbf{2 \%})\end{array}$ & 1292 \\
\hline
\end{tabular}


Nas relações simétricas não-solidárias, observa-se o predomínio da forma $o$ (a) senhor (a) em todos os períodos sob análise, exceto no último quarto do século $\mathrm{XX}$. Os resultados encontrados para o último quarto do século XX podem ser um indício de que as relações tornaram-se menos formais e o emprego de uma forma que indique o tratamento mais distanciado pode ser substituído por uma estratégia menos marcada pela formalidade.

No que diz respeito às formas pronominais, antes de qualquer comentário, é importante ressaltar, no terceiro quarto do século XIX, a presença de vós, que, segundo Cintra (1986 [1972]), já no século XVIII era considerado um traço arcaizante. Com relação ao uso dos outros pronomes, tu prevalece sobre você no século XIX, já no século XX, você predomina sobre $t u$.

\subsection{A distribuição das formas nas relações assimétricas}

As relações assimétricas são aquelas em que há poder na interação entre os interlocutores, ou seja, um interlocutor detém poder sobre o outro. Poder, nesse caso, é compreendido como controle que um dos participantes da situação comunicativa exerce sobre seu interlocutor. Esse tipo de relação corresponde às relações verticais, na categorização de Kerbrat-Orecchioni (2006). Neste trabalho, como já exposto, será adotada a distinção entre relações descendentes (em que quem detém poder é o falante) e ascendentes (em que quem detém o poder é o interlocutor).

\subsubsection{As relações assimétricas descendentes}

$\mathrm{Na}$ amostra sob análise, o tratamento assimétrico descendente é observado na fala do pai dirigida a seu filho; do tio, a seu sobrinho; do patrão, a seu empregado, entre outras. Esperava-se que as TDs evocadas nesse tipo de relação se assemelhassem às encontradas nas relações simétricas solidárias, visto que, nos dois tipos de relação, acredita-se na predominância do tratamento mais íntimo.

De antemão, é necessário esclarecer que não foram identificadas relações assimétricas descendentes nas obras "Amor com amor se paga", de 1870, e "Comunhão de bens", de 1980. Tal fato se deve à temática das peças, que tratam fundamentalmente de conflitos entre casais.

Para análise desse tipo de relação na amostra brasileira, levantou-se um total de $\mathbf{6 3 8}$ dados, que estão distribuídos do seguinte modo:

Tabela 4: A distribuição dos dados nas relações assimétricas descendentes na amostra.

\begin{tabular}{|c|c|c|c|c|c|}
\hline FT & $\mathrm{TU}$ & VOCÊ & SR. & SN & TT \\
\hline $\mathbf{X X}(\mathbf{3})$ & $\begin{array}{r}140 / 154 \\
(\mathbf{9 1 \% )}\end{array}$ & $\begin{array}{l}7 / 154 \\
(5 \%)\end{array}$ & $\begin{array}{l}1 / 154 \\
(\mathbf{1 \% )}\end{array}$ & $\begin{array}{l}6 / 154 \\
(4 \%)\end{array}$ & 154 \\
\hline XIX (4) & - & - & $\begin{array}{c}3 / 4 \\
(75 \%)\end{array}$ & $\begin{array}{c}1 / 4 \\
(25 \%)\end{array}$ & 4 \\
\hline
\end{tabular}




\begin{tabular}{|c|c|c|c|c|c|}
\hline $\mathbf{X X}(1)$ & $\begin{array}{l}77 / 224 \\
(34 \%)\end{array}$ & $\begin{array}{c}120 / 224 \\
(\mathbf{5 4 \%})\end{array}$ & $\begin{array}{l}27 / 224 \\
(\mathbf{1 2 \%})\end{array}$ & - & 224 \\
\hline $\mathbf{X X}(2)$ & - & $\begin{array}{c}46 / 49 \\
(94 \%)\end{array}$ & $\begin{array}{l}3 / 49 \\
(6 \%)\end{array}$ & - & 49 \\
\hline $\mathbf{X X}(3)$ & - & $\begin{array}{l}87 / 97 \\
(\mathbf{9 0 \% )}\end{array}$ & $\begin{array}{l}10 / 97 \\
(\mathbf{1 0 \%})\end{array}$ & - & 97 \\
\hline $\mathrm{XX}(4)$ & - & $\begin{array}{l}110 / 110 \\
(\mathbf{1 0 0 \%})\end{array}$ & - & - & 110 \\
\hline Total & $\begin{array}{c}217 / 638 \\
(34 \%)\end{array}$ & $\begin{array}{c}371 / 638 \\
\mathbf{( 5 8 \% )}\end{array}$ & $\begin{array}{l}44 / 638 \\
(\mathbf{7 \%})\end{array}$ & $\begin{array}{l}\text { 7/638 } \\
\text { (1\%) }\end{array}$ & 638 \\
\hline
\end{tabular}

De uma maneira geral, é possível constatar dois comportamentos distintos das formas de tratamento ao interlocutor ao longo dos séculos XIX e XX. Por um lado, observa-se, inicialmente, nas terceiro quarto do século XIX, o emprego predominante do pronome $t u$, com índice de $91 \%$. Por outro, a forma você, a partir do século $\mathrm{XX}$, passa a predominar, com índices extremamente elevados, principalmente a partir do segundo quarto desse século, chegando a ser categórico no último quarto do século XX. A exceção a esses resultados fica por conta da obra de Machado de Assis (último quarto do século XIX), em que há o predomínio da forma o senhor, esta encontrada na fala de uma senhora mais velha dirigida a um rapaz mais jovem, em que ambos não têm intimidade entre si.

Tomando os resultados, nota-se a mesma tendência observada nas relações simétricas solidárias, em que há o emprego predominante de $t u$ no terceiro quarto do século XIX e a substituição por você nas obras do século XX, fazendo com que essa forma assuma o papel de principal estratégia de tratamento do superior para o inferior. Tais resultados confirmam novamente os dados de Paredes Silva (2000), Soto (2001), Sales (2000) e Lopes e Duarte (2003).

\subsubsection{As relações assimétricas ascendentes}

$\mathrm{O}$ tratamento ascendente corresponde àquele em que um receptor detém poder sobre um emissor. Tal tipo de relação é perceptível, no corpus analisado, na fala de filho para o pai, do sobrinho para o tio, do empregado para o patrão, do escravo para seu senhor, entre outras.

Antes de iniciar a análise dessas relações na amostra brasileira, é importante esclarecer que na peça de 1980 não foram identificadas relações assimétricas.

Nas demais obras, foram encontrados 491 dados nesse tipo de relação, distribuídos da seguinte maneira: 
Tabela 5: A distribuição dos dados nas relações assimétricas ascendentes na amostra.

\begin{tabular}{|c|c|c|c|c|c|c|c|}
\hline FT & TU & VOCÊ & Vós & $\begin{array}{c}\text { V.M. (e } \\
\text { variantes) }\end{array}$ & SR. & SN & TT \\
\hline XIX (3) & $\begin{array}{l}1 / 128 \\
(\mathbf{1 \%})\end{array}$ & - & - & $\begin{array}{l}22 / 128 \\
(\mathbf{1 7 \%})\end{array}$ & $\begin{array}{l}34 / 128 \\
(27 \%)\end{array}$ & $\begin{array}{l}71 / 128 \\
(\mathbf{5 5 \%})\end{array}$ & 128 \\
\hline XIX (4) & $\begin{array}{c}1 / 1 \\
(\mathbf{1 0 0} \%)\end{array}$ & - & - & - & - & - & 1 \\
\hline $\mathbf{X X}(1)$ & - & $\begin{array}{l}4 / 100 \\
(4 \%)\end{array}$ & $\begin{array}{l}3 / 100 \\
(3 \%)\end{array}$ & - & $\begin{array}{l}82 / 100 \\
(82 \%)\end{array}$ & $\begin{array}{l}11 / 100 \\
(\mathbf{1 1 \%})\end{array}$ & 100 \\
\hline $\mathbf{X X}(2)$ & - & $\begin{array}{l}3 / 70 \\
(4 \%)\end{array}$ & - & - & $\begin{array}{c}66 / 70 \\
(94 \%)\end{array}$ & $\begin{array}{l}1 / 70 \\
(2 \%)\end{array}$ & 70 \\
\hline $\mathbf{X X}(\mathbf{3})$ & - & $\begin{array}{l}22 / 95 \\
(\mathbf{2 3 \%})\end{array}$ & - & - & $\begin{array}{l}73 / 95 \\
(77 \%)\end{array}$ & - & 95 \\
\hline $\mathbf{X X}(4)$ & $\begin{array}{l}2 / 97 \\
(2 \%)\end{array}$ & $\begin{array}{l}36 / 97 \\
(36 \%)\end{array}$ & - & - & $\begin{array}{c}59 / 97 \\
(61 \%)\end{array}$ & - & 97 \\
\hline Total & $\begin{array}{l}4 / 491 \\
(\mathbf{1 \% )})\end{array}$ & $\begin{array}{l}\text { 65/491 } \\
(\mathbf{1 3 \%})\end{array}$ & $\begin{array}{l}3 / 491 \\
(\mathbf{1 \% )}\end{array}$ & $\begin{array}{c}22 / 491 \\
(\mathbf{4 \%})\end{array}$ & $\begin{array}{c}314 / 491 \\
(64 \%)\end{array}$ & $\begin{array}{l}83 / 491 \\
(\mathbf{1 7 \%})\end{array}$ & 491 \\
\hline
\end{tabular}

No tratamento assimétrico ascendente, predomina o emprego de $o(a)$ senhor (a) em todos os períodos sob análise, exceto o terceiro quarto do século XIX. No terceiro quarto do século XIX, as formas mais produtivas são os SNs (principalmente, nhanhã e nhonhô, encontrados na fala do escravo a seus senhores), o(a) senhor(a) e variantes de V.M, nesta ordem de produtividade.

Na segunda metade do século XX, apesar da forma $o(a)$ senhor (a) predominar, já se observa significativos índices da forma pronominal você, 23\% e 36\%, no terceiro e quarto quartos do século XX, respectivamente.

Por fim, é importante ressaltar que a flexibilização das relações no domínio assimétrico ascendente é sensivelmente menor do que a encontrada nas relações simétricas não solidárias. Aparentemente, o tratamento de um inferior a seu superior ainda é mais conservador do que aquele que existe entre pessoas em uma situação comunicativa em que não se observa poder nem intimidade entre os participantes desta.

\section{CONSIDERAÇÕES FINAIS}

As discussões desenvolvidas ao longo deste estudo podem ajudar a esclarecer, ao lado de outros trabalhos sobre o tema, a trajetória das formas de tratamento no Rio de Janeiro dos séculos XIX e XX. A análise dos resultados obtidos através da observação das formas de tratamento ao interlocutor, nas quatorze peças teatrais que constituíram a amostra investigada, propiciaram um interessante panorama. 
De antemão, é fundamental reiterar que, neste estudo, as formas de tratamento ao interlocutor são consideradas Tradições Discursivas, visto que se entende que estas são textos evocados em situações comunicativas específicas. Acreditase também que alterações tanto na semântica das formas quanto na natureza das relações sociais tenham gerado contextos em que duas ou mais estratégias competem em um mesmo domínio. Essa competição é o que tradicionalmente se conhece como variação linguística. No decorrer do estudo, busca-se entender, sobretudo, esses contextos de variação - o que se mostra essencial na medida em que se investigam as mudanças no sistema de tratamento ao interlocutor.

A análise dos dados deteve-se a estratégias de referência ao interlocutor na função de sujeito tanto peno quanto nulo com verbos no modo indicativo e subjuntivo. Inicialmente realizou-se uma explanação da distribuição geral das formas, em que se observou uma simplificação do paradigma da referência à segunda pessoa, a partir do segundo quarto do século XX. A partir desse período, o sistema de tratamento parece se restringir às formas você e $o(a)$ senhor $(a)$, com o crescente predomínio daquela sobre esta. Embora tenha diminuído bastante sua frequência de uso, o pronome $t u$ não desaparece completamente nas peças brasileiras. Porém, as marcas verbais de $2^{\mathrm{a}}$ pessoa originais não acompanham mais o pronome no material analisado, no último quarto do século XX.

Com relação à análise das relações sociais estabelecidas, observou-se que o sistema de tratamento ao interlocutor, nas relações simétricas solidárias e nas relações assimétricas descentes, vivencia três momentos distintos. (a) No primeiro momento, no século XIX e no primeiro quarto do século XX, o tratamento se dá predominantemente através do pronome $t u$, embora este possa ter dado lugar a você já na passagem do século XIX para XX, como se verifica na obra de Machado de Assis, de 1896, e nos apontamentos dos trabalhos de Biderman (1975) e Paredes Silva (2000). (b) No segundo momento, no segundo e terceiro quartos do século $\mathrm{XX}$, a referência ao interlocutor ocorre praticamente de maneira categórica com a forma você. (c) No final do século XX, existe a variação entre as formas você e $t u$, esta em seu emprego não-padrão, ou seja, acompanhada pela flexão do verbo na $3^{\mathrm{a}}$ pessoa. Os resultados obtidos ratificam outros estudos sobre o tema.

Já nas relações simétricas não-solidárias e nas relações assimétricas ascendentes, observa-se o predomínio da forma o $(a)$ senhor (a) em praticamente todos os períodos sob análise, com índices dessa forma um pouco superiores nas relações assimétricas ascendentes do que nas relações simétricas não-solidárias. Cabe sublinhar que, nas relações simétricas não-solidárias, no último quarto do século XX, a forma $o(a)$ senhor(a) é substituída parcialmente por você que predomina sobre as demais estratégias e, embora não seja a forma preponderante, nas relações simétricas ascendentes apresenta índices bastante significativos, no último quarto do século XX.

A escalada dessa forma pronominal, aliás, é um dos fatos que merece destaque. Se, no primeiro quarto do século XX, correspondia a cerca de $20 \%$ do total de ocorrências encontradas nas relações simétricas não-solidárias, no último quarto desse século, atinge um percentual próximo a $80 \%$. Tal fato pode indicar que as relações marcadas pelo distanciamento entre os interlocutores caminham 
em direção à intimidade. Essas mudanças estão relacionadas, principalmente, às transformações vivenciadas no interior das sociedades que, a partir, principalmente, de meados do século XX, sobretudo, no espaço da família, tendem a flexibilizar as relações de poder. Tal fato fica bastante evidente com o aumento do uso de você, que se sobrepõe ao emprego de formas de base nominal. Estas aparentemente sobrevivem como formas cristalizadas pela Tradição, e não por sua semântica de distanciamento.

\section{REFERÊNCIAS}

BARCIA, L. R. As formas de tratamento em cartas de leitores oitocentistas: peculiaridades do gênero e reflexos da mudança pronominal. Dissertação de Mestrado em Letras Vernáculas (Língua Portuguesa). Rio de Janeiro: UFRJ, Faculdade de Letras, 2006, 142 fl. Mímeo.

BIDERMAN, M. T. C.. Formas de Tratamento e Estruturas Sociais. Alfa. São Paulo: FFCL de Marília, No 18/19, 1972. p.339-381.

BROWN, R.; GILMAN, A. The pronouns of power and solidarity. In: PAULSTON, C. B.; TUCKER, G. R. (Ed.). Sociolinguistics: The essencial readings. United Kingdom: Blackwell, 2003 [1960]. p. $156-176$.

CINTRA, L. F. L. Sobre “formas de tratamento" na língua portuguesa. 2. ed. Lisboa: Livros Horizonte, 1986. (Coleção Horizonte).

FARACO, C. A. O tratamento você em português: uma abordagem histórica. In: Fragmenta 13, Publicação do Curso de Pós-Graduação em Letras da UFPR. Curitiba, Editora da UFPR, 1996.

KABATEK, J. "Tradições discursivas e mudança linguística", In: LOBO, T.; RIBEIRO, I.; CARNEIRO, Z.; ALMEIDA, N. (eds.). Para a história do português brasileiro: novos dados, novas análises. Salvador: EDUFBA, 2006.

KeRBRATT-ORECCHIONI, C. Análise da conversação. Principio classes e Métodos. São Paulo: Parábola Editorial, 2006

LABOV, W. Padrões sociolinguísticos. São Paulo: Parábola Editorial, 2008.

LOPES, C. R. dos S. et al.. História do Português Brasileiro: mudança das classes de palavras: perspectiva funcionalista. São Paulo: Contexto, 2018.

LOPES, C. R. dos S; COUTO, L. R.; DUARTE, M. E. L. Como as pessoas se tratam no cinema latino-americano: análise de formas de tratamento em roteiros de três países, Memórias - XIV Congresso Internacional da ALFAL. Monterrey : ALFAL, 2005. v.1.

LOPES, C. R. dos S; DUARTE, M. E. L. De 'Vossa Mercê'a 'você': a análise pronominalização de nominais em peças brasileiras e portuguesas setecentistas e oitocentistas. In: BRANDÃO, S. F.; MOTA, M. A. (orgs.). Análise contrativa de variedades do português. Primeiros estudos. Rio de Janeiro, In-Fólio, 2003. 
LOPES, C. R. dos S; MACHADO, A. C. M. Tradição e inovação: indícios do sincretismo entre segunda e terceira pessoas nas cartas dos avós. In: LOPES, Célia Regina dos Santos (org.). Norma brasileira em construção: fatos lingüísticos em cartas pessoais do século XIX. Rio de Janeiro: Pós-Graduação em Letras Vernáculas/FAPERJ, 2005, v. , p. 45-66.

LOREGIAN-PENKAL, L. (Re)análise da referência de segunda pessoa na fala da região sul. Tese (Doutorado em Linguística). Universidade Federal do Paraná. Curitiba 2004.

MACHADO, A. C. M.. A implementação de você no quadro pronominal: as estratégias de referência ao interlocutor em peças teatrais no século XX. Dissertação de Mestrado em Letras Vernáculas - Língua Portuguesa. Faculdade de Letras/ UFRJ, Rio de Janeiro, 2006.

MENON, O. P. da S.; LOREGIAN-PENKAL, L. Variação no indivíduo e na comunidade: tu/você no sul do Brasil. In: VANDRESEN, P. (org.) Variação e mudança no Português falado da região sul. Pelotas, Educat, 2002.

PAREDES SILVA, V. L. O percurso da variação na referência à segunda pessoa no português carioca. Relatório final de pesquisa apresentado ao CNPq. Rio de Janeiro, UFRJ,1999. Mimeo. 35 p.

PAREDES SILVA, V. L. A distribuição dos pronomes de segunda pessoa do singular na fala carioca ao longo do século XX. II Congresso Nacional da Abralin (CD-rom), 2000.

PAREDES SILVA, V.L.. O retorno do pronome $t u$ à fala carioca. In: RONCARATI, C.; ABRAÇADO, J. (orgs.). Português brasileiro - contato lingüistico, heterogeneidade e história. 1 ed. Rio de Janeiro: 7letras/FAPERJ, 2003, v. 1, p. 160-179.

ROBINSON, W. P. Linguagem e comportamento social. Trad. Jair Martins. São Paulo, Cultrix, 1977 [1972].

RUMEU, M. C. de B. Para uma história do português no Brasil: formas pronominais e nominais de tratamento em cartas setecentistas e oitocentistas. Dissertação de Mestrado em Letras Vernáculas - Língua Portuguesa. Faculdade de Letras/ UFRJ, Rio de Janeiro, 2004.

RUMEU, M. C. de B. A implementação do 'você' no português brasileiro oitocentista e novecentista: um estudo de painel. Tese de Doutorado em Letras Vernáculas - Língua Portuguesa. Faculdade de Letras/ UFRJ, Rio de Janeiro, 2008.

SALES, M. Pronomes de tratamento do interlocutor no português brasileiro: um estudo de pragmática histórica. 2001. Tese (Doutorado em Filologia e Língua Portuguesa) - Faculdade de Filosofia, Letras e Ciências Humanas/ USP, São Paulo, 2001.

SOTO, E. Variação/Mudança do pronome de tratamento alocutivo: uma análise enunciativa em cartas brasileiras. Tese de Doutorado em Linguística e Língua Portuguesa, Araraquara, Universidade Estadual Paulista "Julio de Mesquita Filho", 2001.

WEINREICH, U., LABOV, W.; HERZOG, M. Fundamentos empíricos para uma teoria da mudança lingüística. Tradução de Marcos Bagno. Revisão Técnica de Carlos Alberto Faraco. Posfácio de Maria da Conceição e Maria Eugênia Lamoglia Duarte. São Paulo: Parábola Editorial, 2006. 


\section{AS OBRAS QUE COMPÕEM A AMOSTRA}

ALENCAR, J. [1857] O demônio familiar. In: www.dominiopublico.com.br

AMARAL, M. A. de. (1995) Intensa Magia. Rio de Janeiro, SBAT. Mímeo.45 p.

ARAÚJO, A. (1980) Comunhão de bens. Rio de Janeiro, SBAT. Mímeo. 78 p.

BARBOSA, M. C.; FALABELLA, M. (2004 [2003]) Síndromes. In: Querido Mundo e outras peças. Rio de Janeiro, Lacerda

BLOCH, P. Dona Xepa. (1973 [1952]) Rio de Janeiro: Serviço Nacional De Teatro (Coleção Dramaturgia Brasileira).

COELHO NETTO, H. M. (1957 [1908]) Quebranto. In: Revista de Teatro da SBAT. Rio de Janeiro, $1957\left(n^{\circ} 295\right)$.

FRANÇA JUNIOR, J.J. [1870] Amor com amor se paga. In: www.dominiopublico.com.br

FRANÇA JUNIOR, J.J. [1870] O defeito de família. In: www.dominiopublico.com.br

GILL, G. (1964 [1962]) Toda donzela tem um pai que é uma fera. Rio de Janeiro, Tempo Brasileiro.

GONZAGA, A. (1937) O hóspede do quarto número 2. Rio de Janeiro, SBAT. Mímeo.

MACHADO DE ASSIS, J. [1896] Não Consultes Médico. In: www.dominiopublico.com.br

PENA, M. [1846] Os Ciúmes de um Pedestre. In: www.dominiopublico.com.br

ROCHA, A. O Genro Que Era Nora. (1979 [1972]) In: Revista de Teatro da SBAT. Rio de Janeiro.

TOJEIRO, G. (1966 [1918]) O Simpático Jeremias. In: Revista de Teatro da SBAT. Rio de Janeiro. 